\title{
Review of magnetism and heavy metal pollution studies of various environments in Argentina
}

\author{
Marcos A. E. Chaparro ${ }^{1,2}$, Claudia S. G. Gogorza ${ }^{1,2}$, Mauro A. E. Chaparro ${ }^{2,3}$, María A. Irurzun ${ }^{1,2}$, Ana M. Sinito ${ }^{1,2}$ \\ ${ }^{1}$ IFAS, Universidad Nacional del Centro de la Provincia de Buenos Aires, Pinto 399, 7000 Tandil, Argentina \\ ${ }^{2}$ CONICET, Rivadavia 1917, 1033 Ciudad Autónoma de Buenos Aires, Argentina \\ ${ }^{3}$ Instituto Multidisciplinario de Ecosistemas y Desarrollo Sustentable, Universidad Nacional del Centro \\ de la Provincia de Buenos Aires, Pinto 399, 7000 Tandil, Argentina
}

(Received December 14, 2005; Revised April 28, 2006; Accepted May 8, 2006; Online published November 8, 2006)

\begin{abstract}
In recent years, the number of studies of pollution and magnetic proxies for environmental pollution in developed countries, especially European and North American countries, has gradually increased from the 80's to date. Despite this trend that shows a positive interest in taking care of the environment and researching into the environmental impact of several human activities, pollution studies in Latin American countries have been reducing in number. Moreover, studies of magnetic proxies for pollution are scarce; in particular, studies of this nature has been carried out in Argentina over the past few years by Chaparro and coworkers. Studies of magnetic enhancement in soils due to the burning mechanism are discussed and the results of burnt soils affected by fires of different nature and natural soils are compared, taking into account their magnetic carriers. Nevertheless, this article deals mainly with the first studies of magnetic proxies for pollution conducted in a province in Argentina. Soils, lagoon and stream sediments from three areas were studied. These areas comprise La Plata, Chascomús, and Tandil districts. The influence of pollution was investigated in Tandil and La Plata, revealing magnetic enhancement and the presence of pollutants only in Tandil soils. On the other hand, stream and lagoon sediments were studied in La Plata and Chascomús. Magnetic carriers and the contents of some heavy metals were identified and investigated in both areas separately. Magnetic parameters show distinctive points and wide areas affected by pollution. Furthermore, this magnetic inference is supported by high contents of heavy metals, especially lead and zinc. Finally, a new statistical study of multiple correlation analysis concerning data from La Plata and Chascomús areas was tried in order to investigate the existence of a linear relation between sets of several magnetic parameters and several chemical variables.
\end{abstract}

Key words: Magnetism, magnetic enhancement, pollution, stream sediments, soils.

\section{Introduction}

Human impact, especially atmospheric pollution, in urban and natural media has increased its adverse potential in the last years. So, pollution has become a subject widely investigated from several fields, such as, physics, geology, geophysics, chemistry, etc. According to Petrovský and Ellwood (1999), atmospheric pollution is identified as one of the most harmful factors for ecosystems. Often, industrial and urban fly ashes included toxic elements and heavy metals; such airborne pollutants are diffused due to atmospheric circulation. Land environments undergo a major impact, because pollutants are transferred to the Earth's surface, made available, and taken by organisms, or incorporated into sediments.

In environmental magnetism and rock-magnetism, magnetic techniques have been successfully developed and improved, becoming a very useful tool in order to investigate and understand processes occurring in different environments. Among studies in this research field, magnetic minerals and in situ changes in sediment environs and

Copyright (c) The Society of Geomagnetism and Earth, Planetary and Space Sciences (SGEPSS); The Seismological Society of Japan; The Volcanological Society of Japan; The Geodetic Society of Japan; The Japanese Society for Planetary Sciences; TERRAPUB. soils, mainly, by anthropogenic influence are focussed in this work.

From the point of view of Environmental Magnetism, Thompson and Oldfield (1986), Petrovský and Ellwood (1999), Evans and Heller (2003) discussed and presented reviews of the most relevant European and North American works in this related topic. A large number of exhaustive studies of pollution and magnetic proxies for pollution have been conducted in developed countries from the 80's to date (e.g. Beckwith et al., 1986; Strzyszcz et al., 1993, 1996; Flanders, 1994; Morris et al., 1994; Versteeg et al., 1995; Georgeaud et al., 1997; Heller et al., 1998; Scholger, 1998; Bityukova et al., 1999; Durza, 1999; Kapicka et al., 1999; Hoffmann, 1999; Magiera and Strzyszcz, 1999; Matzka and Maher, 1999; Petrovský et al., 2000; Knab et al., 2001, 2006; Boyko et al., 2002, 2004; Hanesch and Scholger, 2002; Schibler et al., 2002; Jordanova et al., 2003a,b, 2004; Lecoanet et al., 2003; Pozza et al., 2004; Desenfant et al., 2004; Spiteri et al., 2005; Magiera et al., 2006, etc.).

Conversely, pollution studies in the Third World (e.g. in China: Zhang and Yu, 2002; Hu et al., 2003; Wang and Qin, 2005, 2006a,b, in Hong Kong: Chan et al., 2001, in India: Goddu et al., 2004; Das, 2005, in Korea: Jung et al., 2005; Park et al., 2005, in Nepal: Gautama et al., 2004a,b, 2005, 
in Nigeria: Fakayode and Olu-Owolabi, 2003, in Turkey: Yuce et al., 2006, in Thailand: Szczucinski et al., 2005, etc.) and Latin American Countries (e.g. in Brazil: Gioia et al., 2006; in Chile: Chirinos et al., 2006; in Mexico: Rosales Hoz et al., 2004, 2005; in Puerto Rico: Acevedo-Figueroa, 2001 and Acevedo-Figueroa et al., 2006, etc.) are reduced in number.

In Argentina, in particular, biochemical, geochemical and chemical studies concerning urban pollution have been mainly carried out in the most densely populated province: Buenos Aires Province. Among the published works, Ronco et al. (1995, 2001), Manassero et al. (1998), Colombo et al. (1999, 2005), Bilos et al. (2001), Quaranta et al. (2002), Mazzeo et al. (2005) can be cited. Nevertheless, studies of magnetic proxies for pollution in Argentina are really scarce; the works discussed in the next sections (Chaparro, 1999; Chaparro et al., 2000, 2002a,b, 2003, 2004a,b, 2005) are some of the first carried out in South America.

\section{Some Aspects of Background and Fundamen- tals in Environmental Magnetism \\ 2.1 Magnetic carriers}

A minor fraction of magnetic mineral often handles the magnetic signal of soils (stream, river and lake), sediments and rocks. Within this fraction, ferromagnetic materials, i.e. ferrimagnetic and antiferromagnetic minerals stand out. In most cases, the ferromagnetic concentration does not surpass $1 \%$, which is enough to control and mask the diamagnetic and paramagnetic signal from specimens.

Differences and discrimination among magnetic carriers are possible according to their magnetic response, e.g. values of specific susceptibility $(\chi)$ vary widely for these magnetic carriers: diamagnetic $\left(\sim-6 \times 10^{-9} \mathrm{~m}^{3} \mathrm{~kg}^{-1}\right)$, paramagnetic $\left(\sim 10^{-6} \mathrm{~m}^{3} \mathrm{~kg}^{-1}\right)$, antiferromagnetic ones $(\sim 6-$ $\left.7 \times 10^{-7} \mathrm{~m}^{3} \mathrm{~kg}^{-1}\right)$, and ferrimagnetic $\left(\sim 0.5-5.6 \times 10^{-3} \mathrm{~m}^{3}\right.$ $\left.\mathrm{kg}^{-1}\right)$. For detailed $\chi$ values and other magnetic parameters, the reader is addressed to Thompson and Oldfield (1986), Bartington Inst. Ltd (1994), Maher et al. (1999), etc.

Industrial and urban activities emit and release dust particles, mainly fly ash, directly into the atmosphere; these particles can include heavy metals and other toxic elements. According to Petrovský and Ellwood (1999) and other authors, fly ash is often consists of ferromagnetic materials, and their grain size vary from submicron to micron range, respirable $(<2.5 \mu \mathrm{m})$ and inhalable $(2.5-10 \mu \mathrm{m})$ aerosols.

In an environment, magnetic "prints" are obtained from the magnetic features of carriers, and the use of magnetic parameters for pollution assessment and other studies in magnetism is supported by the mentioned fact. However, magnetic prints can undergo distortions and changes from the media, chemical transformations, weathering, climatic influences, etc.

\subsection{Magnetic enhancement}

First evidence of magnetic enhancement was noted by Le Borgne (1955), subsequent studies of many authors (e.g. Tite and Linington, 1975; Mullins, 1977) confirmed this phenomenon. Magnetic enhancement can occur in many ways, involving natural and anthropogenic processes.
The anthropogenic process (e.g. industrial activities, vehicle traffic) consists of extra influx of magnetic particles including heavy metals. The natural processes comprise in situ conversion of non-ferromagnetic iron minerals into ferromagnetic minerals, and extra influx of magnetic particles from terrestrial and extraterrestrial origin. Among these processes, it is possible to identify fermentation, lithogenesis, biogenesis, pedogenesis, chemical processes, volcanic activity, cosmogenic/meteorite ablation, and burning (Vadiunina and Babanin, 1972; Mullins and Tite, 1973; Tite and Linington, 1975; Mullins, 1977; Thompson et al., 1980; Thompson and Oldfield, 1986; Maher, 1986; Petrovský and Elwood, 1999).

In this work, magnetic enhancement due to burning (see Section 5.1. Burning soils) and anthropogenic influence (see Section 5.2 and Section 5.3) were only investigated.

\subsection{Magnetic monitoring of anthropogenic pollution}

The magnetic susceptibility method in magnetism has been very well accepted for mapping anthropogenic heavy metal pollution. Although the magnetic proxy technique uses a whole range of rock magnetic techniques, only magnetic susceptibility can be measured in the field by using Bartington Ltd., ZH Ltd., and other instruments. This method has become useful because it uses only one single parameter, magnetic susceptibility (Petrovský and Ellwood, 1999). Measurements are easy, prompt and cost-effective to carry out. So, it becomes possible to establish dense grids of sites under study (e.g. Hanesch and Scholger, 2002; Schibler et al., 2002; Boyko et al., 2004), and therefore, to produce $2 \mathrm{D}$ or $3 \mathrm{D}$ maps of magnetic parameters, which could be used as proxies of certain pollutants. However, the linkage between contents of pollutants and magnetic parameters has to be proven by additional studies. It allows us to assess the contamination for reduced or wide extensions in a qualitative way. Several authors have proved the efficacy and usefulness of the method, among them: Strzyszcz (1993), Strzyszcz et al. (1996), Hanesch and Scholger (2002), Jordanova et al. (2003a).

\subsection{Magnetic parameters and heavy metals}

The concentration of toxic elements and magnetic particles - magnetite, maghemite, hematite and many more magnetic phases of extremely complicated compositionin anthropogenic emissions depend on various factors. However, very often magnetite-like phases (of sphere-like shape) are dominan. According to Kukier et al. (2003), differences in final pollutant products are related to the characteristics of combustible material, combustion conditions, and protection facilities. Both concentrations of pollutants and magnetic particles can be linked because they are genetically related. Nevertheless, different factors and influences may dilute linkage between them.

Vassilev (1992), Petrovský and Ellwood (1999), Kukier et al. (2003), and other authors, have proved that both concentrations are related because magnetic particles can act as hosts of heavy metals and other pollutants. The host role for magnetic particles can be achieved in two ways, either a magnetic particle may include heavy metals onto its crystalline structure during combustion and its subsequent generation, or after formation, it may adsorb heavy metals on its surface. 

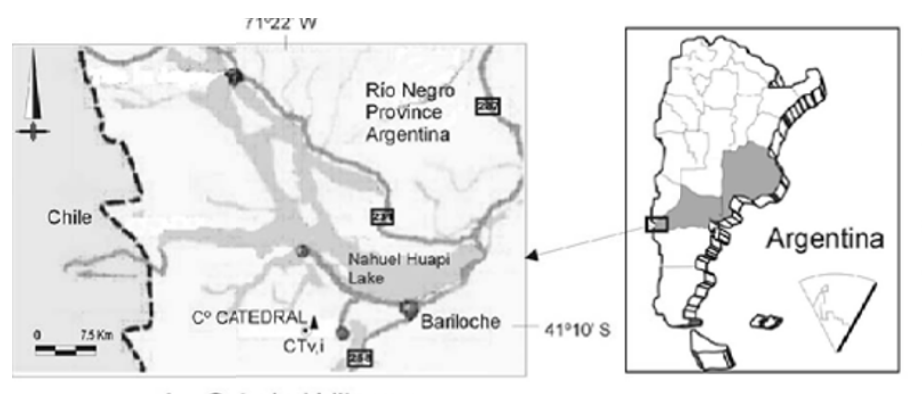

1a. Catedral hill area (Rio Negro province)
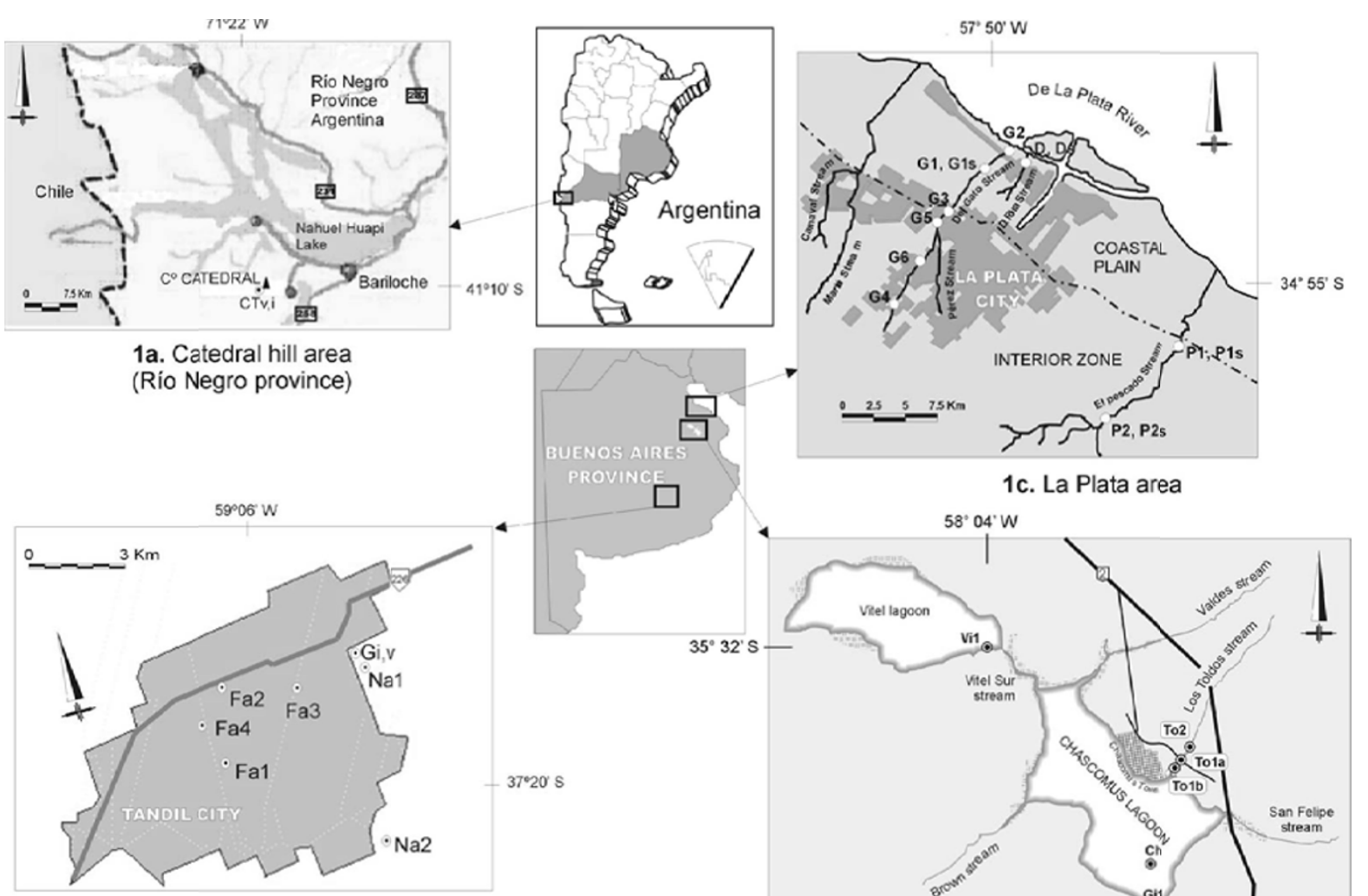

1b. Tandil area

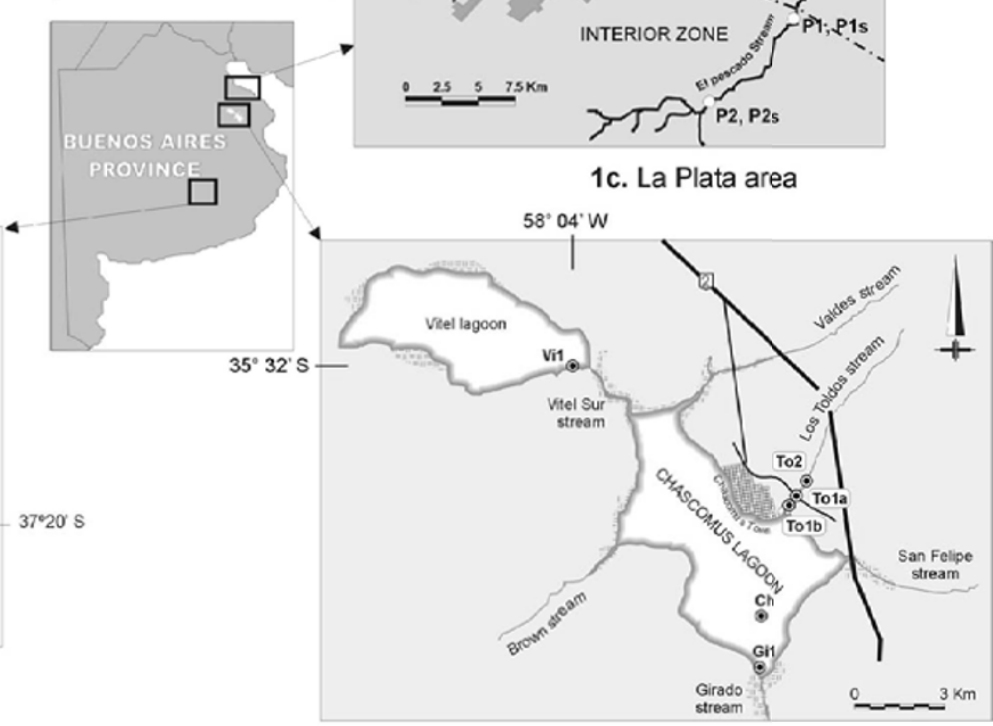

1d. Chascomús area

Fig. 1. Map of studied areas from Argentina. Sampling sites belong to the Río Negro and Buenos Aires provinces. In particular, 1a. Soils from Catedral Hill area (CTv,i,); 1b. Soils from the Tandil area (Gv,i, Na.1-2, Fa.1-4); 1c. Soils (G1s, Ds, P1-2s) and sediment cores from La Plata area (G1-6, D, P1-2); 1d. Sediments cores from the Chascomús area (To1-2, Vi1, Ch and Gi1) are pinpointed.

Although magnetic susceptibility proved to be a good and qualitative proxy for contamination in a large number of studies, other magnetic parameters have been investigated as indicators of heavy metal pollution. Various studies showed bad correlations among magnetic susceptibility and heavy metals, whereas alternative magnetic parameters (e.g. remanent magnetisations) correlated very well.

Relationships between magnetic parameters and heavy metals have become an interesting subject of investigation in magnetic monitoring and a large number of papers have been devoted to it, e.g. Hunt et al. (1984), Beckwith et al. (1986); Strzyszcz et al. (1996), Petrovský et al. (1998, 2000), Heller et al. (1998), Bityukova et al. (1999), Durza (1999), Hoffmann et al. (1999), Kapicka et al. (1999), Hanesch and Scholger (2002); Chaparro et al. (2004b).

\section{Sites and Locations under Study in Argentina}

As was pointed out before, magnetism studies in Argentina are scarce. In the following sections, works concerning magnetism of soils and sediments are discussed.

Burning soils were studied in the Rio Negro Province, Bariloche City, Catedral Hill zone (CT, $\left.41^{\circ} 10^{\prime} \mathrm{S} ; 71^{\circ} 22^{\prime} \mathrm{W}\right)$; and in the Buenos Aires Province, Tandil City $\left(37^{\circ} 20^{\prime} \mathrm{S}\right.$; $\left.59^{\circ} 06^{\prime} \mathrm{W}\right)$, Golf Club zone (G), see Fig. 1. At each zone, two soils, burning (subscript i, CTi and Gi) and unaffected (subscript v, CTv and Gv) soils were studied.

On the other hand, magnetism studies concerning indus- trial and urban pollution were investigated in the densely populated province of Buenos Aires. Areas under study, La Plata $\left(34^{\circ} 55^{\prime} \mathrm{S} ; 57^{\circ} 50^{\prime} \mathrm{W}\right)$, Chascomús $\left(35^{\circ} 32^{\prime} \mathrm{S} ; 58^{\circ} 04^{\prime} \mathrm{W}\right)$ and Tandil areas $\left(37^{\circ} 20^{\prime} \mathrm{S} ; 59^{\circ} 06^{\prime} \mathrm{W}\right)$ can be appreciated in Fig. 1. Soils are pinpointed in the Tandil area (soils near metallurgical factories, Fa1-4, and soils in natural zones, $\mathrm{Na1-2)}$, and in the La Plata area (soils near polluted sites, G1s, Ds, and soils in unpolluted sites, P1s and P2s), as can be observed in Fig. 1. Stream and lagoon sediment cores were collected in the La Plata area (sites near polluted sites, G1-6, D, and unpolluted sites, P1 and P2), and in the Chascomús area (stream sediments cores, To1-2, lagoon sediments cores, Ch, Gi1 and Vi1).

All studied soils and sediments in the urban sites (Tandil, La Plata and Chascomus city) were controlled in order to avoid the recent influences of anthropogenic activities, such as construction, reworking, landfill, etc., that can cause pollution and magnetic misinterpretations.

The soils classify as Argiudolls (SAGyP-INTA, 1989); their pedological description and the main minerals were detailed in Chaparro et al. (2000, 2002a, 2004a). Geological setting of streams and lagoons are not discussed in this article either. For details, the reader is addressed to Chaparro et al. (2003, 2004a,b, 2005). The sediment core descriptions and the main minerals are also detailed in the above-mentioned articles. 


\section{Techniques and Methods}

Soils from the Rio Negro and Buenos Aires provinces were studied in depth and in three surface layers $(\mathrm{S}: 0 \mathrm{~cm}$, 1: $10 \mathrm{~cm}$ and 2: $20 \mathrm{~cm}$ ). In situ magnetic susceptibility was measured and samples were collected from each soil. Sediments and soils from the Buenos Aires province were sampled by collecting sediment cores, plastic bags, and specimens in plastic boxes in depth to perform laboratory magnetic and non-magnetic measurements. The sample preparation (drying, sieving, and consolidation) and measurements were carried out by using a previously defined procedure or protocol (for details, see Chaparro et al., 2000, 2002a, 2003, 2004a,b, 2005; Chaparro, 2006).

Among the magnetic techniques, magnetic susceptibility $(\kappa)$, anhysteric remanent magnetisation (ARM), isothermal remanent magnetisation (IRM), magnetic demagnetisation, temperature-dependent susceptibility, and thermal demagnetisation were used. The following instruments were used: (a) a magnetic susceptibility meter MS2 (Bartington Instruments Ltd.) linked to a MS2B dual frequency sensor (470 and $4700 \mathrm{~Hz}$ ) and MS2F; (b) a partial ARM (pARM) device attached to a shielded demagnetizer (Molspin Ltd.); (c) a spinner fluxgate magnetometer Minispin (Molspin Ltd.); (d) a pulse magnetizer model IM-10-30 (ASC Scientific); (e) a Shielded Demagnetizer (Molspin Ltd.); (f) a devise and complementary equipment for measurements of temperature-dependent susceptibility; (g) a thermal specimen demagnetizer, model TD-48 (ASC Scientific).

Curves, plots and related parameters mentioned in this manuscript are specific magnetic susceptibility $(\chi)$, frequency-dependent $\kappa\left(\kappa_{\mathrm{FD}} \%\right)$, anhysteric susceptibility $\left(\kappa_{\mathrm{ARM}}\right)$, King's plot ( $\kappa_{\mathrm{ARM}}$ versus $\kappa$, King et al., 1982) and $\kappa_{\text {ARM }} / \kappa$-ratio (Dunlop and Özdemir, 1997), IRM acquisition curves, saturation of IRM (SIRM), SIRM/ $\chi$, remanent coercivity $\left(H_{C R}\right)$, S-ratios, demagnetization curves, median destructive field (MDF), $\kappa$-T curves, stepwise thermal demagnetization curves, Curie temperature $\left(T_{C}\right)$. Measurement procedures and settings are not detailed in this article. However, for details, see Chaparro et al. (2000, 2002a, 2003, 2004a,b, 2005).

$\mathrm{X}$-ray diffraction studies were realised by using an automatic Philips PW1710 X-ray diffractometer with graphite monochromated $\mathrm{Cu}-\mathrm{K}$ radiation, automatic divergence slit, and a scan speed of $0.005^{\circ} 2 \theta \mathrm{s}^{-1}$. The spectroscopic behaviour of some samples was analysed by means of Fourier Transform infrared spectroscopy (FTIR). Infrared spectra were recorded on a Nicolet-Magna 550 FTIR instrument, using the $\mathrm{KBr}$ pellet technique.

Traces of heavy metals were determined by spectrometry of atomic absorption; the samples were dried and prepared by using the protocol: "3050 acid digestion of sediments, sludge and soil" (Environmental Protection Agency, EPA SW-846, 1986; APHA, AWWA, WEF, 1998).

\section{Results and Discussion}

\subsection{Burning in soils}

Burning is one of the mechanisms identified as a major factor in magnetic enhancement (Mullins, 1977). In Chaparro et al. (2000), two different environments from the Rio Negro and Buenos Aires provinces were inves-
Table 1. Mean values of in situ magnetic susceptibility of each layer (S, 1 and 2) for virgin (CTv and Gv) and burnt (CTi and Gi) soils. Percent increments for each layer are also displayed.

\begin{tabular}{lccc}
\hline Soil & \multicolumn{3}{c}{ In situ magnetic susceptibility } \\
& \multicolumn{3}{c}{$\left(10^{-5} \mathrm{SI}\right)$} \\
\hline & Layer S & Layer 1 & Layer 2 \\
& $(0 \mathrm{~cm})$ & $(10 \mathrm{~cm})$ & $(20 \mathrm{~cm})$ \\
$\mathrm{Gv}$ & 42.7 & 319.2 & 612.0 \\
$\mathrm{Gi}$ & 383.3 & 696.2 & 727.6 \\
Increment $(\%)$ & 797 & 118 & 19 \\
$\mathrm{CTV}$ & 271.4 & 963.8 & 934.9 \\
$\mathrm{CTi}$ & 835.7 & 897.2 & 963.8 \\
Increment $(\%)$ & 207 & -7 & 3 \\
\hline
\end{tabular}

tigated. Although two zones are studied and presented in this work, they are not compared with each other regarding their pedological differences, as well as their fire intensity. Forest fires over long periods and during the past years took place in soil CTi from Catedral Hill. The recent fire history and events in this area were published by national graphic and visual media; on the other hand, some of the past fire history from 13,000 yr B.P. to present is discussed in Bianchi (2000). Moreover, the problem has become of special government interest and it has carried out a National Program of Forest StatisticStatistics of Forest Fire since 1999 (Ministerio de Salud y Ambiente-Argentina, annual reports can be downloaded in http://www.medioambiente.gov.ar/?idarticulo=303). On the other hand, minor fires occurred in soil Gi from Tandil (Fig. 1). In the surrounding areas of burning soils, virgin or natural soils, soil CTv for site CT, and soil Gv for site G, were sampled in order to carry out a comparison with baseline values from unaffected soil. Such "unaffected" soils were chosen according to the limits of the burnt areas (e.g. the forest fire in Bariloche in 1997) that were photographically documented. It is worth mentioning that this choice does not exclude the occurrence of previous fires.

Results of in-situ magnetic susceptibility $\left(\kappa_{\mathrm{is}}\right)$ for both sites are listed in Table 1. From these results, it is possible to see magnetic enhancement in the upper section of soils, especially layer S. Similar results were obtained in Tite and Linington (1975) and Thompson et al. (1980). The percentage of increase in layer $\mathrm{S}$, between virgin and burnt soils, clearly shows that magnetic enhancement took place, reaching increments of $207 \%$ for soils CT and $797 \%$ for soils G. SIRM results of samples from layer S support this behaviour, revealing higher values for $\mathrm{CTi}$ and $\mathrm{Gi}$ (10.9 and $3.7 \times 10^{-2} \mathrm{~A} \mathrm{~m}^{2} \mathrm{~kg}^{-1}$, respectively) than for $\mathrm{CTV}$ and $\mathrm{Gv}$ (7.4 and $0.8 \times 10^{-2} \mathrm{~A} \mathrm{~m}^{2} \mathrm{~kg}^{-1}$, respectively).

It is worth mentioning that the $\kappa_{\text {is }}$ parameter for deeper layers (layers 1 and 2) tends toward similar values for virgin and burnt soils (Table 1); such a result supports the common origin of these soils. The heating depth affecting materials in these soils can also be estimated from these results.

Feature-dependent magnetic parameters, $\kappa_{\mathrm{FD}} \%, H_{C R}$ and S100-ratio, allow us to know and characterise the main magnetic carriers. Values of $\kappa_{\mathrm{FD}} \%$ are below $5 \%$, so superparamagnetic grains do not control the assemblages of magnetic grains (Bartington Inst. Ltd., 1994). Ferrimag- 
netic minerals are expected in both sites, $H_{C R}$ varies from 33.7 to $43 \mathrm{mT}$ for soils $\mathrm{G}$, and from 46.3 to $56 \mathrm{mT}$ for soils CT. S-ratio is $\sim 0.73$ for soils $G$, and $\sim 0.45$ for soils CT. From both parameters, the presence of antiferromagnetic minerals is also deduced in soils CT, especially in the virgin soil CTv. Values of $H_{C R}$ parameter for soils CT and G show differences between layer $\mathrm{S}$ and the deeper ones, indicating a higher content of ferrimagnetic minerals in surface layers of both sites.

\subsection{Magnetic proxies for pollution in soils}

5.2.1 Soils from Tandil area In this work, anthropogenic pollutants from metallurgical factories and their influences in the nearest soil were the main goal. Magnetic enhancement, as consequence of the above-mentioned influence, was specially investigated. Considering the recent pollution history in the Tandil area, pollutants in soil profiles are expected in the uppermost horizon, A-horizon or mollic epipedon (these soils are classified as Argiudolls, SAGyP-INTA, 1989).

Tandil is a relatively small town of $\sim 108,000$ inhabitants that has a reduced number of industrial factories (about 0.2 per $\mathrm{km}^{2}$ ). These factories are located in the urban zone, and although the pollution problem is relatively young and not of long-term, results in Chaparro et al. (2002a) revealed that released pollutants of adverse consequences for environment and human health are incorporated in soils horizons.

According to Chaparro et al. (2002a) and Chaparro (1999, 2006), a distinctive magnetic behaviour for unpolluted and polluted soils in the Tandil region was detected. Magnetic susceptibility and SIRM, concentrationdependent magnetic parameters, are higher for soils belonging to the industrial sites (four sites: soils Fa1-4) than for soil in natural areas (two sites: Na1-2), e.g., $\kappa$ differences are notorious, $467-760 \times 10^{-5}$ SI for soils Fa1-4 and 39$192 \times 10^{-5}$ SI for soils Na1-2, and since all studied samples and profiles belong to the same pedological horizon, within the mollic epipedon, the influence of pollutant particles in industrial sites (soils Fa1-4) can be confirmed. Estimation of magnetic concentration showed that magnetite concentration is about $0.01 \%$ in natural areas and $0.1 \%$ in industrial areas.

In addition to such a difference between sites, magnetic enhancement in soils Fa1-4 seems to take place in all layers (S, 1 and 2) up to $20 \mathrm{~cm}$. In Fig. 2, magnetic enhancement of a typical polluted soil can be appreciated for soil Fa1.

Although ferrimagnetic oxides are found in both sites, their magnetic features vary slightly. Taking into account feature-dependent parameters, such as coercivity of remanence, S100-ratio and $\kappa_{\mathrm{FD}} \%$, magnetically soft ferrimagnetic materials (e.g. magnetite) control industrial sites. On the other hand, a balance between ferri and antiferromagnetic minerals is found in natural sites. Rough estimations in magnetic grain size reveal single domain (SD)/pseudo single domain (PSD) magnetite in sites Fa1-4, and finer grain size, SD and, in some cases, with contribution of superparamagnetic magnetite in sites Na1-2. Other studies, temperature dependence of susceptibility, FTIR studies and X-ray diffraction spectra (see Chaparro et al., 2002a) support some of the above-mentioned conclusions.

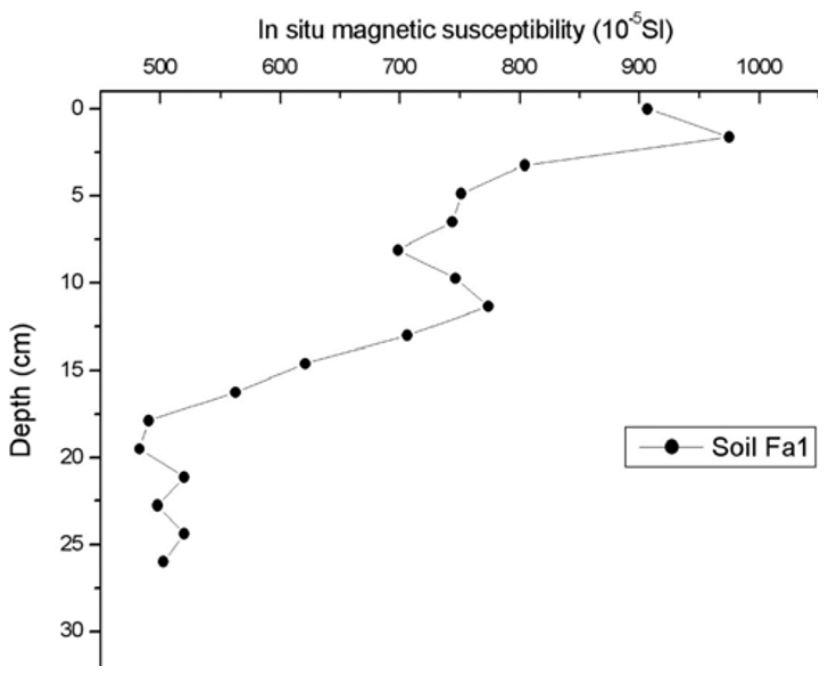

Fig. 2. In-situ magnetic susceptibility measurements in depth for soil Fa1 (soil near a metallurgical factory) from the Tandil area. Magnetic enhancement can be appreciated in the upper sequence. From Chaparro (1999).

Contents of some heavy metals, $\mathrm{Cd}, \mathrm{Fe}, \mathrm{Ni}, \mathrm{Pb}$ and $\mathrm{Zn}$, were also determined in order to establish their presence in these soils and their possible linkage with magnetic enhancement. Pollution status in soils Fa1-4 is confirmed through higher values of $\mathrm{Pb}$ (up to $222.8 \mathrm{mg} / \mathrm{kg}$ ) and $\mathrm{Zn}$ $(173.3 \mathrm{mg} / \mathrm{kg}$. In spite of few chemical determinations $(n=6)$, an analysis of linear regression between magnetic susceptibility and contents of heavy metals was performed. Correlations are good, $\mathrm{R}=0.64$ for $\chi-\mathrm{Pb}, R=0.64$ for $\chi$ $\mathrm{Zn}, R=0.61$ for $\chi$-Cd, $R=0.66$ for $\chi$-Total concentration, $R=0.17$ for $\chi-\mathrm{Ni}$, and $R=0.17$ for $\chi-\mathrm{Fe}$. Although these results must be interpreted considering that $n$ is small $(n=5)$ for statistics, these first results are relatively good, and comparable to other earlier studies in Europe (Hunt et al., 1984; Beckwith et al., 1986; Heller et al., 1998; Durza, 1999). Nevertheless, magnetic susceptibility values in the Tandil area are lower than in North American and European countries. This fact can be related (in terms of pollution) to a low level of pollution, possibly due to the young industrial history.

5.2.2 Soils from la plata area Soils from the La Plata area were investigated (Chaparro et al., 2002b, 2004a) after previous studies in stream sediments had been conducted. As Chaparro et al. (2003, 2004b) found (see Section 5.3.1, Stream sediment from La Plata area) sediments from a cross-city stream (Del Gato stream, Fig. 1) have been affected by industrial and urban pollution. Regarding pollution influences in stream sediments from this area, another environment was investigated in order to assess contamination impact in soils near the core-collecting sites.

La Plata is one of the most populated cities in Buenos Aires Province. It has $\sim 600,000$ inhabitants and a population density of $\sim 585$ inhabitants per $\mathrm{km}^{2}$. According to Cabral et al. (2002), the current land use in the La Plata area is classified into urban, industrial, waste land, residential areas, intensive farmland, forest, extensive cattle raising areas, quarries, etc.

In this area, the soils show differences in their pedolog- 


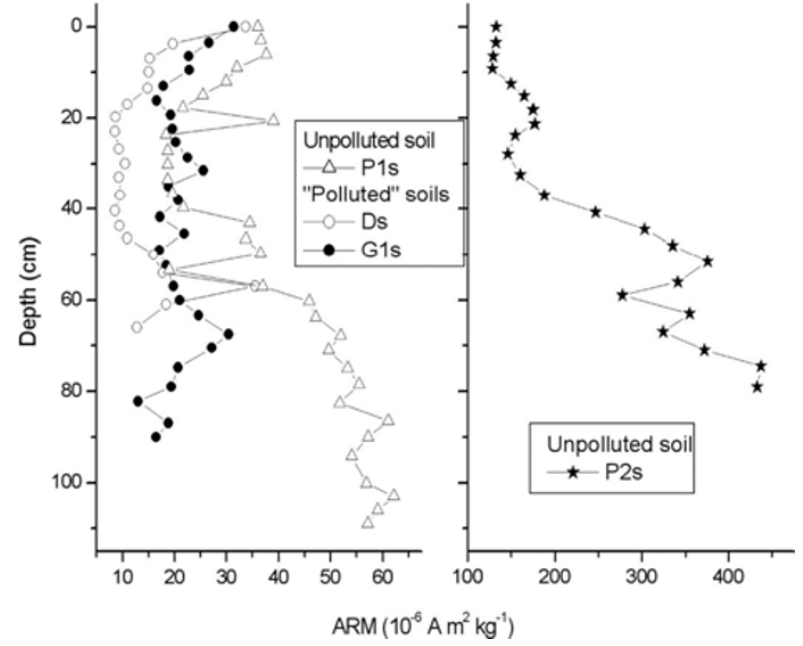

Fig. 3. ARM versus depth for soil "polluted" soils (G1s and Ds) and unpolluted soils (P1s and P2s) from La Plata. Pedological A-horizons vary from 0 to $8 \mathrm{~cm}$ (soil G1s), from 0 to $15 \mathrm{~cm}$ (soil Ds), from 0 to $20 \mathrm{~cm}$ (soil P1s), and from 0 to $10 \mathrm{~cm}$ (soil P2s). Although magnetic enhancement does not occur, differences between A and B-horizons are observed. From Chaparro et al. (2004a).

ical development. Possibly polluted soils, G1s and Ds, developed in the coastal plain zone (Fig. 1), have recently formed and are waterlogged for long periods during the year because of their low topographic position. Argiudol soils (SAGyP-INTA, 1989) are better developed in P2 site where soil P2s was sampled. Mixed soils-developed in marine as well as in continental deposits - are representative of the soil P1s.

Concentration-related magnetic parameters $(\chi$, ARM and SIRM) showed low values that seem not to be connected with pollution. Specific magnetic susceptibility values are similar between "polluted" soils (G1s and Ds) and unpolluted soil (P1s), varying from 10.7 to $20.5 \times 10^{-8} \mathrm{~m}^{3}$ $\mathrm{kg}^{-1}$. On the other hand, the unpolluted soil $\mathrm{P} 2 \mathrm{~s}$ reached the highest values $\left(37.2-93.2 \times 10^{-8} \mathrm{~m}^{3} \mathrm{~kg}^{-1}\right)$. According to its location, geological background, and the poor pollution influence, the ARM-depth behaviour for soil P2s (see Fig. 3) can be explained in terms of soil formation features, and not in pollution terms.

A homogeneous behaviour among soils G1s, Ds and $\mathrm{P} 1 \mathrm{~s}$, without remarkable differences, is observed. Although magnetic enhancement seems not to take place in the upper horizon, a slight magnetic increase in ARM parameter is evidenced in A-horizon in relation to B-horizon (Fig. 3). From measurements of $\chi$ and SIRM, Thompson plot (Thompson and Oldfield, 1986), magnetite concentrations in these soils vary between 0.001 and $0.01 \%$. Such concentrations are lower than in polluted soils (see Section 5.2.1. Soils from the Tandil area).

Soft ferromagnetic oxides are predominant in all soils according to the analyses of the S-ratio and $H_{C R}$ parameter. Magnetite, especially, is the main magnetic carrier, with PSD grains ranging between 0.2 and $5 \mu \mathrm{m}$ (from King Plot, King et al., 1982). In soils G1s, Ds and P1s, carriers of Ahorizon are finer and magnetically softer than in B-horizon.

On the other hand, contents of heavy metals $(\mathrm{Pb}, \mathrm{Cu}, \mathrm{Zn}$,
$\mathrm{Ni}, \mathrm{Cr}, \mathrm{Fe}$ and $\mathrm{Mn}$ ) rarely surpass the allowed mean values for natural environments (Frink, 1996). Among these heavy metals, only $\mathrm{Zn}$ and $\mathrm{Mn}$ reached twice and three times the amv (detailed results can be found in Chaparro et al., 2004a).

A clear magnetic and chemical distinction between unpolluted and "polluted" soils was not obtained. The low level of contents of heavy metals, mostly around the amv, and the low and narrow range of $\chi$ values for soils G1s, Ds and $\mathrm{P} 1 \mathrm{~s}$, are not enough to correspond to pollutant loads. In spite of the fact that some stream sediments sites are contaminated, its close corresponding soils seem not to be affected by pollution. As was stated in Chaparro et al. (2004a), maybe, the main pollution input is via liquid effluents or the distances to the sources are too far for atmospheric contamination.

\subsection{Magnetic proxies for pollution in stream and la- goon sediments}

5.3.1 Stream sediments from La Plata area Stream sediments in urban and rural zones from the La Plata area were investigated in two campaigns. This area receives industrial and urban pollutants that especially affect a crosscity stream (Del Gato stream). Del Gato, Dona Flora and El Pescado streams run in this area (see Fig. 1) and were studied in a preliminary work (Chaparro et al., 2003) and in a subsequent work (Chaparro et al., 2004b), establishing a detailed study of magnetic carriers in sediments and their relationship with heavy metal loads.

As was mentioned in Section 5.2.2, La Plata is one of the most populated cities of the Buenos Aires Province. According to Manassero et al. (1998), the estimated population living on both banks of the Del Gato stream is approximately 70,000 inhabitants. There are more than 300 point sources of pollution derived from the chemical industry, metallurgy, wood and paper mills, non-treated urban sewage (Ronco et al., 1995, 2001; Alzuet et al., 1996) and plants of waste disposal. Another important source of pollution is the traffic on city and open roads. In the northeast of Buenos Aires Province, previous geochemical studies showed a high level of some trace elements, especially $\mathrm{Cu}$, $\mathrm{Pb}$ and $\mathrm{Zn}$, on stream sediments (Manassero et al., 1998; Ronco et al., 2001).

The preliminary study of magnetic proxies for pollution in this area (Chaparro et al., 2003) confirmed pollution influences in sediment columns, on the first $20 \mathrm{~cm}$ in depth. Concentration-related magnetic parameters $(\chi$, ARM and SIRM) showed clear differences between sites $P$ (El Pescado stream) and sites G and D (Del Gato and Dona Flora streams, Fig. 1); higher values of these parameters were found for sites $G$ and D. These magnetic parameters showed magnetic enhancement in the uppermost sediments of sites $\mathrm{G}$, and in the middle part of core D; such enhancement can be observed in Fig. 4 for $\chi$ and ARM parameters. On the other hand, lower $\chi$ and ARM values for the El Pescado stream behaved as unpolluted sites: cores P1a and P2c have been established as background values in La Plata area. Background values vary from 6.1 to $28.6 \times 10^{-8}$ $\mathrm{m}^{3} \mathrm{~kg}^{-1}$ for $\chi$, and from 9.2 to $53.9 \times 10^{-6} \mathrm{~A} \mathrm{~m}^{2} \mathrm{~kg}^{-1}$ for ARM. It is worth mentioning that the values of sites $G$ and $\mathrm{D}$ trend to the background values for sediments deeper than 


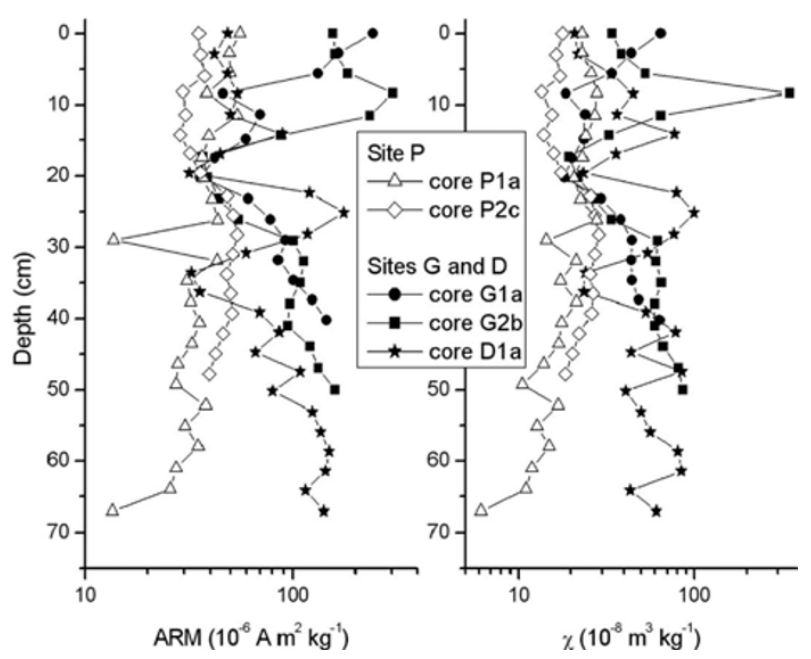

Fig. 4. ARM and specific magnetic susceptibility versus depth for stream sediments from the La Plata area are displayed. Cores from sites P belong to the El Pescado stream and cores from sites G and D belong to the Del Gato and Dona Flora streams. From Chaparro et al. (2003, 2004a).

$20 \mathrm{~cm}$. Thus, such a result supports the common origin of sediments from all streams and suggests the pollution influence in the uppermost sediments from the Del Gato stream.

Measurements of contents of heavy metals $(\mathrm{Pb}, \mathrm{Cu}, \mathrm{Zn}$, $\mathrm{Ni}$ and $\mathrm{Fe}$ ) showed clear differences between both sites as well, supporting the above-mentioned conclusions about magnetic enhancement in sites $\mathrm{G}$ and $\mathrm{D}$. Contents of $\mathrm{Pb}, \mathrm{Cu}$ and $\mathrm{Zn}$ highly surpass the $a m v$ (Frink, 1996). These values reached up 12 times the $a m v$, i.e. 233,69 and $406 \mathrm{mg} / \mathrm{kg}$ for $\mathrm{Pb}, \mathrm{Cu}$ and $\mathrm{Zn}$, respectively.

Magnetic characterisation of carrier, magnetomineralogy and magnetic grain size, was analysed from IRM and pARM curves, S-ratio, $H_{C R}, \mathrm{SIRM} / \chi, \mathrm{MDF}, \kappa_{\mathrm{ARM}} / \kappa-$ ratio, temperature dependence of magnetic susceptibility and thermal demagnetisation studies (for details, see Chaparro et al., 2003). The integrated analysis revealed the predominance of ferrimagnetic minerals in all sediment cores, magnetite being the main magnetic carrier among them. The presence of secondary soft carriers such as titanomagnetite and maghemite is also possible. Besides these magnetic carriers, a minor proportion of hard magnetic (antiferromagnetic) minerals, maybe hematite or goethite, is expected. Magnetic grain size distribution is another remarkable and distinctive feature to take into account for these sediments. Finer grain sizes occur in the upper sediment sequence of cores $G$ and $D$. This is especially significant in cores $\mathrm{G}$ and has been related to the input of pollutants. Quantitative estimations from King plot (King et al., 1982) reveal magnetic grain sizes between 0.2 and $1 \mu \mathrm{m}, \mathrm{PSD} / \mathrm{SD}$ grains.

Finally, in this early work, magnetic conclusions of qualitative status of pollution were quantified through analysis of linear regression between ARM and the contents of heavy metals $(\mathrm{Pb}, \mathrm{Cu}, \mathrm{Zn}, \mathrm{Ni}$ and $\mathrm{Fe})$. Correlations were good, varying between 0.4293 and 0.7363 (for detailed results see Chaparro et al., 2003, 2004b).

In Chaparro et al. (2004b), special attention was paid to the Del Gato stream according to the pollution impact in sediments found in the preliminary work. So, new sampling sites (sites G3, G4, G5 and G6, Fig. 1) were sampled and analysed in order to improve and increase the magnetic mapping in this polluted stream.

Spatial (from the head to the mouth of the stream) and vertical behaviour of Del Gato stream sediments was studied. Cores were divided into two groups according to their location within the geomorphologic zones: Interior Zone and Coastal Plain (Fidalgo and Martinez, 1983, see Fig. 1).

Sediments of each group seem to have an independent behaviour. From a previous geochemistry study, Ronco et al. (2001) also found such discrimination. Although cores from the Coastal group (G1 and G2) show magnetic enhancement and strong heavy metal increase in the upper section of the sediment column, on the other hand, all cores from the Interior group (G3, G4, G5 and G6) do not show a clear magnetic enhancement, especially cores G4 and G5. However, $\chi$ and ARM values are found to be as high as those in the Coastal group (Chaparro et al., 2004b). Concentration of ferrimagnetic minerals, especially magnetite, is estimated between 0.01 and $0.1 \%$ for both groups. This range is relatively high and similar to the one found in polluted Tandil soils (see Section 5.2.1). The occurrence of finer grain size and softer magnetic carriers at the uppermost sediment is a distinctive feature of sediments from both groups as well. As was concluded before, it is related to the input of pollutants in the first $20 \mathrm{~cm}$ deep section. According to Chaparro et al. (2004b), such a recent anthropogenic influence belongs to the last 20-40 years; it is based on a deposition rate of $0.5-1.0 \mathrm{~cm}$ per year (Manassero et al., 1998).

Relationship between the magnetic parameters-also considering $\kappa_{\mathrm{ARM}} / \kappa$-ratio and S-ratio-and the contents of heavy metals were investigated for cores $\mathrm{G}$ as well. Correlations from analysis of linear regression can be observed in detail in Chaparro et al. (2004b). In particular, correlations with feature-dependent magnetic parameters $\left(\kappa_{\mathrm{ARM}} / \kappa\right.$-ratio and S-ratio) are better than with concentration-dependent magnetic parameters ( $\chi$ and ARM). The most relevant parameter in this work is $\kappa_{\mathrm{ARM}} / \kappa$-ratio; $R$ coefficient reaches very good values of up to 0.9229 at a high level of significance.

Spatial distribution of heavy metals (mainly $\mathrm{Pb}$ and $\mathrm{Zn}$ ) and magnetic carriers in the Del Gato stream shows an increase towards the mouth of the stream in the Coastal Plain. According to Ronco et al. (2001) and Chaparro et al. (2004b), this zone behaves as a sink, retaining and accumulating pollutants in the environment.

5.3.2 lagoon and stream sediments from chascomus area Magnetism studies in another area in Buenos Aires Province and the relevance of various magnetic parameters, as pollution indicators, were the main topics discussed in this work (Chaparro et al., 2005).

The Chascomús area comprises the lacunar system of De Las Encadenadas de Chascomús, which is located in the NE of Buenos Aires Province, and in the SW of La Plata. Among the lagoons and streams sampled and studied in this system, we chose Vitel and Chascomús lagoons, and Los Toldos and Girado streams (Fig. 1). The Los Toldos stream 


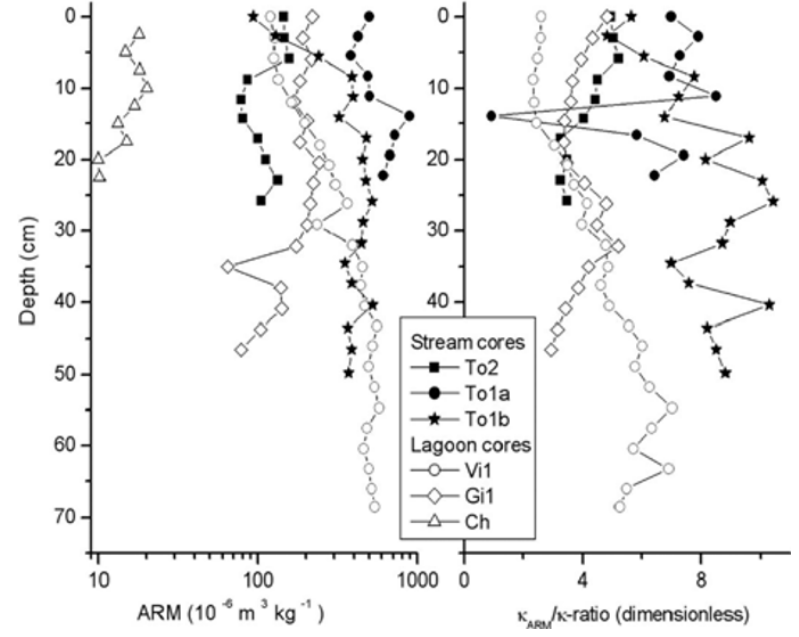

Fig. 5. ARM and $\kappa_{\mathrm{ARM}} / \kappa$-ratio versus depth for lagoon and stream sediments from the Chascomús area are displayed. Lagoon sediment cores belong to Chascomús and Vitel lagoons, stream sediment cores belong to the Los Toldos streams. From Chaparro et al. (2005).

source is located near a national road (Route 2) with high vehicle traffic, and crosses the Chascomús suburban district where various factories might be polluting the stream (Dangavs et al., 1996). The town of Chascomús is a small town in Buenos Aires Province. It has 29,000 inhabitants, public buildings, tourist facilities as well as some industries which are located on the eastern shore of the lagoon.

Concentration-dependent magnetic parameters show a similar behaviour; $\chi$ and SIRM patterns are coherent with ARM pattern, latter measurements are displayed in Fig. 5. Magnetic enhancement is observed in the Los Toldos stream, especially, in cores To1a and To1b where $\chi$ parameter reaches an extreme value of $1395.0 \times 10^{-8} \mathrm{~m}^{3} \mathrm{~kg}^{-1}$. ARM, $\chi$ and SIRM parameters are higher for cores To1a and Tolb than for the others (for detailed values, the reader is addressed to Chaparro et al., 2005). These results suggest a local influence of pollution in Los Toldos stream. Moreover, chemical studies support and confirm this magnetic inference; contents $\mathrm{Pb}$ and $\mathrm{Zn}$ are clearly higher for core To1a (94.7 and $220.9 \mathrm{mg} / \mathrm{kg}$, respectively) than for cores Gi1 and Vi1 (37.2 and $76.0 \mathrm{mg} / \mathrm{kg}$, respectively).

Magnetite is the main magnetic carrier. However, secondary hard magnetic carriers (possibly hematite) are also expected from feature-dependent magnetic parameters $\left(H_{C R}\right.$ and S-ratio). Such a possibility was further investigated using a new experimental method of magnetic discrimination (Chaparro and Sinito, 2004). Besides, the hard magnetic component was confirmed in some samples; each magnetic component was characterised as well (e.g. sample To2-6, contribution $($ phase 2$)=24.7 \%, H_{C R}($ phase 2$)=365.3$ $\mathrm{mT}$, S-ratio (phase2) $=-0.207$ ). A distinction between cores Tola/b and the other cores is observed from the grain size-related parameter, $\kappa_{\mathrm{ARM}} / \kappa$-ratio (see Fig. 5).

Furthermore, $\kappa_{\mathrm{ARM}} / \kappa$-ratio and $H_{C R}$ parameters, as well as the concentration-dependent magnetic parameter, show differences between stream cores and lagoon cores, which can also be related to the pollution influence.

On the other hand, correlations from analysis of lin-

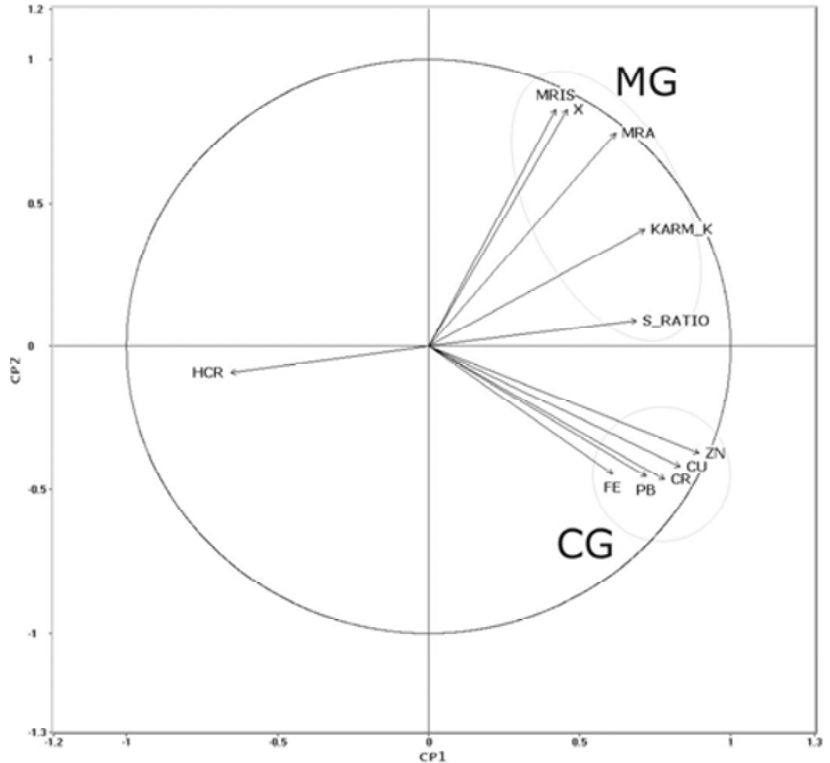

Fig. 6. Biplot of two principal components (CP1 and CP2) using Principal Component analysis (PCA). PCA is performed for data $(n=35)$ from the La Plata and Chascomús areas. From this exploratory statistical method, two groups of variables: magnetic (MG) and chemical (CG) sets are discriminated as a first approximation.

ear regression were performed for five magnetic parameters $\left(\chi, \mathrm{ARM}, \kappa_{\mathrm{ARM}} / \kappa\right.$-ratio, $\mathrm{S}$-ratio and $\left.H_{C R}\right)$ and contents of heavy metals. Correlations are detailed in Chaparro et al. (2005). In this case, the feature-dependent parameters, $\kappa_{\mathrm{ARM}} / \kappa$-ratio and $H_{C R}$, and the concentration-related parameter ARM, correlate very well with some heavy metals (e.g. up to 0.9094 at high level of significance). These results are in agreement with the ones obtained in sediments from the near area of La Plata (Chaparro et al., 2004b), suggesting the $\kappa_{\mathrm{ARM}} / \kappa$-ratio (and possibly ARM) as a relevant indicator of pollution in sediments from the northeast of Buenos Aires Province.

5.3.3 Relationship between magnetic parameters and heavy metals from La Plata and Chascomús area After performing analyses of linear regression for data from La Plata and Chascomús areas separately, a new study concerning both areas and using another statistical analysis, canonical correlation analysis (CCA), was carried out.

There are several measures of correlation to express the relationship between two or more variables. Simple correlation analysis estimates the extent to which two variables are related; multiple correlation analysis estimates the relationship between a variable and a set of variables; on the other hand, CCA allows the investigation of the relationship between two sets of several variables.

In CCA, a data set concerning several variables is considered and grouped into two sets. The use of CCA is appropriated when the study of structure of covariances matrix between two sets of variables is the main analysis aim. Specifically, CCA estimates the correlation among a set of variables Xi and another Yi. Detailed information and discussion of CCA can be found in Johnson and Wichern (1992), Mardia (1980), Anderson (1958), STATISTICA (1995) and other mathematical texts. However, it is not the purpose in 
this section to discuss this topic and only the main concepts and statistics in CCA are briefly introduced.

In this section, calculations for CCA were made by using the software STATISTICA for Windows 5.1. Firstly, 35 samples $(n=35)$ from both areas were selected. Then, two sets of variables were defined from two exploratory statistical methods: Principal Component (PCA) and Cluster (CA) analysis. Both analyses were carried out by using the software Multivariado. From PCA, two groups of variables: magnetic (MG) and chemical (CG) are identified as a first approximation (see Fig. 6). On the one hand, a set of six magnetic variables $\left(\chi, \mathrm{ARM}, \mathrm{SIRM}, \kappa_{\mathrm{ARM}} / \kappa\right.$-ratio, S-ratio and $H_{C R}$ ) labelled set MG and, on the other, a set of five chemical variables $(\mathrm{Pb}, \mathrm{Cu}, \mathrm{Zn}, \mathrm{Cr}$ and $\mathrm{Fe}$ ) labelled set $\mathrm{CG}$. Although $\mathrm{CA}$ results are not shown here, they are in agreement with the PCA results.

Also, two analyses (CCA) were performed in order to confirm the existence of a relationship between set MG and CG: one analysis using a reduced set of data $(n=28)$ and the other one with all data $(n=35)$. In the first case, the reduced set of data was obtained taking out samples with a considerably high level of contamination in order to study the influence of extreme data in both sets of variables.

The last CCA $(n=35)$ improves canonical correlation $(R)$, obtaining better results than the first analysis; in particular, $R=0.89071$ statistically significant $(p=0.00632)$ was achieved. The CCA results are good at a high level of significance; in particular, such results show the existence of a linear relation between groups, magnetic (MG) and chemical (CG) sets. So, according to the $R$ value, one set is explained by the other in $\sim 87 \%$. In Fig. 6 , linear relations and $95 \%$ confidence bands are shown for the analysis $(n=35)$.

This result is coherent with pollution influence, i.e. a bad linkage between MG and CG sets is expected for data of the lowest values or background values. Such a conclusion is supported by the fact of a non-common formation process of magnetic material and heavy metal occurring in nature. Unlike processes in nature, industrial and urban pollution processes often have a common formation origin.

Finally, a new study dividing the set MG was also tried. The set MG was divided into two groups in order to investigate the relevance of variables contributing to the relationship; one group concerning concentration-dependent magnetic parameters (set MG1: $\chi$, ARM and SIRM) and the other one concerning feature-dependent magnetic parameters (set MG2: $\kappa_{\mathrm{ARM}} / \kappa$-ratio, S-ratio and $H_{C R}$ ). Results using these new sets for $n=35$ reveal different canonical $R$, $R=0.58855$ non-statistically significant $(p=0.38897)$ for sets MG1 and CG; and $R=0.75085$ statistically significant $(p=0.01889)$ for sets MG2 and CG. Such results show better correlation for the group of feature-dependent parameters. From CCA calculations, coefficients of canonical weights (not listed here), variables $\mathrm{Pb}$ and $\mathrm{Zn}$ in set $\mathrm{CG}$, and $\kappa_{\mathrm{ARM}} / \kappa$-ratio in set MG have the highest contribution to the relationship between groups. This conclusion is in agreement with previous simple correlation analyses in $\mathrm{La}$ Plata (Chaparro et al., 2004b) and Chascomús areas (Chaparro et al., 2005), where $\kappa_{\mathrm{ARM}} / \kappa$-ratio (S-ratio and $H_{C R}$ ) parameter was found as the most relevant magnetic parameter to describe heavy metal pollution in each area.
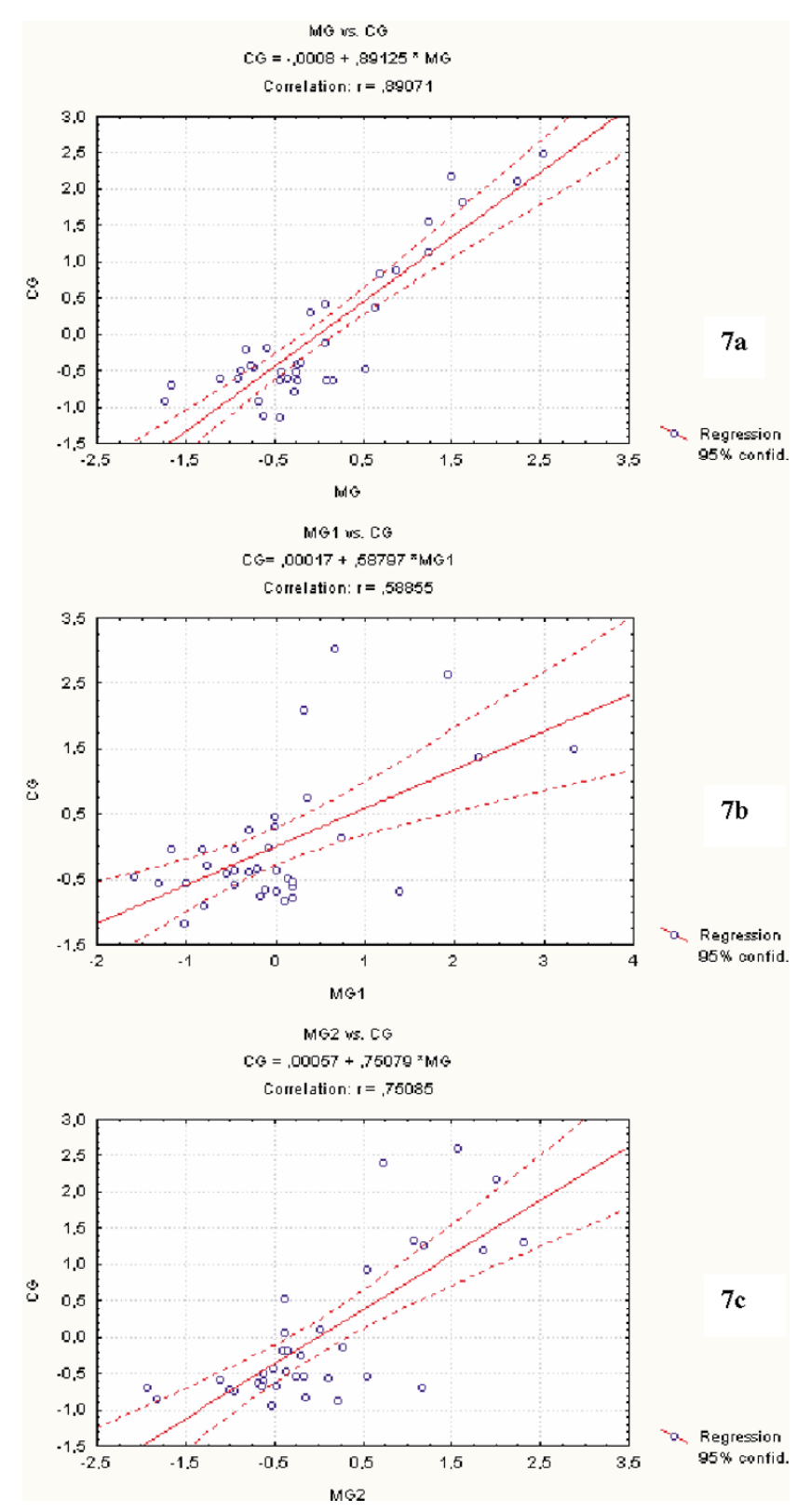

Fig. 7. Statistical study of multiple correlation analysis for data $(n=35)$ from La Plata and Chascomús areas. Linear relation and $95 \%$ confidence bands are shown for: 7a magnetic (MG: $\chi$, ARM, SIRM, $\kappa_{\mathrm{ARM}} / \kappa$-ratio, S-ratio and $\left.H_{C R}\right)$ and chemical (CG: $\mathrm{Pb}, \mathrm{Cu}, \mathrm{Zn}, \mathrm{Cr}$ and Fe) sets; 7b. magnetic (MG1: $\chi$, ARM, SIRM) and chemical (CG) sets; 7c. magnetic (MG2: $\kappa_{\mathrm{ARM}} / \kappa$-ratio, S-ratio and $\left.H_{C R}\right)$ and chemical (CG) sets. The canonical $R$ value $(R=0.89071)$ for MG-CG set is statistically significant showing the existence of a linear relation between groups. The subsequent study of new sets show differences, the canonical $R$ value $(0.58855)$ is non-statistically significant for MG1-CG set, and the canonical $R$ value $(0.75085)$ is statistically significant for MG2-CG set.

\section{Summary and Conclusions}

Burning is identified as a factor causing magnetic enhancement in two different environments from the Rio Negro and Buenos Aires provinces. In-situ magnetic susceptibility measurements and the percentage of increase revealed magnetic enhancement in the upper section of soils. These increments in layer S reach values of $207 \%$ for soils of Catedral and $797 \%$ for soils close to Tandil.

Studies of magnetic proxies for pollution in Tandil reveal 
a distinctive magnetic behaviour for unpolluted and polluted soils. Concentration-dependent magnetic parameters ( $\chi$ and SIRM) are higher for soils belonging to the industrial sites than for soil in natural areas. Moreover, magnetic enhancement in soils near factories seems to take place in all layers up to $20 \mathrm{~cm}$ thick. Chemical determinations are in agreement with this magnetic behaviour, pollution status is confirmed through higher values of $\mathrm{Pb}$ and $\mathrm{Zn}$. On the other hand, studies in soils from La Plata region seem not to be affected by pollution; concentration-related magnetic parameters $(\chi$, ARM and SIRM) showed low values and homogeneous behaviour among soils, without observable remarkable differences. Heavy metal contents rarely surpassed the allowed mean values for natural environments reflecting the pollution status. Although magnetic enhancement seems not to take place in the upper horizon, a slight magnetic increase in ARM parameter is evidenced.

In stream sediments from the La Plata area, the preliminary magnetic proxies for pollution confirmed pollution influences in sediment columns, on the first $20 \mathrm{~cm}$ down. Concentration-related magnetic parameters ( $\chi$, ARM and SIRM) showed clear differences between the unpolluted El Pescado stream and polluted Del Gato and Dona Flora streams. Magnetic enhancement was observed in the uppermost sediments from polluted streams; and contents of $\mathrm{Pb}, \mathrm{Cu}$ and $\mathrm{Zn}$ highly surpass the allowed mean values. On the other hand, lower $\chi$ and ARM values for the El Pescado stream were established as background values in the La Plata area. Another study focussing on the Del Gato stream determines the spatial distribution of magnetic and chemical pollutants (mainly $\mathrm{Pb}$ and $\mathrm{Zn}$ ), showing an increase towards the mouth of the stream. This zone behaves as a sink, retaining and accumulating pollutants in the environment. The occurrence of finer grain size and softer magnetic carriers at the uppermost sediment is a distinctive feature of sediments, and it is related to the input of pollutants in the first $20-\mathrm{cm}$ layer. Such a recent anthropogenic influence belongs to the last 20-40 years. According to correlations from analysis of linear regression, feature-dependent magnetic parameters, especially $\kappa_{\mathrm{ARM}} / \kappa$-ratio, are the most relevant parameters in this area.

Magnetic proxies for pollution in another area, Chascomús, showed magnetic enhancement in a stream; especially magnetic results suggest a local influence of pollution in Los Toldos stream. In addition, chemical studies support and confirm this magnetic inference; contents $\mathrm{Pb}$ and $\mathrm{Zn}$ are clearly higher. $\kappa_{\mathrm{ARM}} / \kappa$-ratio and $H_{C R}$ parameters, as well as concentration-dependent magnetic parameters, show differences between stream cores and lagoon cores, which can also be related to the pollution influence. Correlations from analysis of linear regression showed that feature-dependent parameters ARM are relevant parameters as pollution indicators.

Finally, the new statistical study of multiple correlation analysis concerning La Plata and Chascomús areas confirms the existence of a linear relation between magnetic (MG) and chemical (CG) groups. Canonical correlation is 0.89071 and it is statistically significant. Furthermore, a subsequent study dividing the set MG into MG1 and MG2 revealed an $R=0.75085$ statistically significant for sets MG2 and CG. Consequently, a better correlation for the group of feature-dependent parameters is found. From CCA calculations, variables $\mathrm{Pb}, \mathrm{Zn}$ and the $\kappa_{\mathrm{ARM}} / \kappa$-ratio have the highest contribution to the relationship between groups.

Acknowledgments. The authors wish to thank the Universidad Nacional del Centro de la Provincia de Buenos Aires (UNCPBA), the Agencia Nacional de Promoción Científica y Tecnológica (ANCyT) and the National Council for Scientific Technological Research (CONICET) for their financial support. They are also very grateful to $\mathrm{Mg}$. Claudia Marinelli for her assistance and discussion in statistics subjects. The authors thank the anonymous reviewers for their suggestions as well.

\section{References}

Acevedo-Figueroa, D., Comparative analyses of heavy metals in sediment and water from two coastal lagoons in Puerto Rico, MS thesis, University of Puerto Rico, 160 pp., 2001.

Acevedo-Figueroa, D., B. D. Jiménez, and C. J. Rodríguez-Sierra, Trace metals in sediments of two estuarine lagoons from Puerto Rico, Environ. Pollut., 141(2), 336-342, 2006.

Alzuet, P., E. Gaspes, and A. Ronco, Mutagenecy of environmental samples from an industrialised area of the Río de La Plata Estuary using the Salmonella-Microsomal Assay, Environ. Toxicology and Water Quality, 11, 1231-1236., 1996.

Anderson, T. W., An Introduction to Multivariate Statistical Analysis, Wiley. New York (USA), 1958.

APHA, AWWA, WEF, Standard Methods for the Examination of Water and Wastewater. 20th Edition, 1998.

Bartington Instruments Ltd., Operation manual, Environmental magnetic susceptibility-Using the Bartington MS2 system, Chi Publishing, UK, 54 pp., 1994.

Beckwith, P., J. Ellis, D. Revitt, and F. Oldfield, Heavy metal and magnetic relationships for urban source sediments, Phys. Earth Planet. Int., 42, 67-75, 1986.

Bianchi, M. M., Fire history in Patagonia: Post-Glacial and Holocene charcoal record of Lago Escondido $\left(41^{\circ} \mathrm{S}-72^{\circ} \mathrm{W}\right)$. In Spanish, Revista Cuaternario y Ciencias Ambientales. CADINCUA, COMINCUA. Asociación Geológica Argentina. Publicación Especial 4, vol. 1, 23-29, 2000

Bilos, C., J. C. Colombo, C. N. Skorupka, and M. J. Rodriguez Presa, Sources, distributions and variability of airborne trace metals in La Plata city area, Argentina, Environ. Pollut., 111, 149-158, 2001.

Bityukova, L., R. Scholger, and M. Birke, Magnetic susceptibility as indicator of environmental pollution of soils in Tallin, Phys. Chem. Earth (A), 24(9), 829-835, 1999.

Boyko, T., S. Höll, R. Scholger, and MagProx Team, Anthropogenic and geogenic impacts on magnetic susceptibility anomalies of forest topsoil in Austria, Extended abstract for the International Symposium on Fundamental Rock Magnetism and Environmental Applications, Erice, Italy, n. 26: 11, 2002.

Boyko, T., R. Scholger, H. Stanjek, and MAGPROX TEAM, Topsoil magnetic susceptibility mapping as a tool for pollution monitoring: repeatability of in-situ measurements, J. Appl. Geophys., 55(3-4), 249-259, 2004.

Cabral, M. G., M. A. Hurtado, J. E. Giménez, C. A. Sánchez, D. Muntz, and M. da Silva, Indices de afectación territorial en la planificación estratégica del partido de La Plata, Provincia de Buenos Aires, Argentina. V, Jornadas Geológicas and Geofísicas Bonaerenses, 20 pp., 2002.

Chan, L. S., S. L. Ng, A. M. Davis, W. W. S. Yim, and C. H. Yeung, Magnetic properties and heavy-metal contents of contaminated seabed sediments of Penny's bay, Hong Kong, Mar, Pollution Bull., 42(7), 569_ 583, 2001.

Chaparro, M. A. E., Caracterización magnética de distintos tipos de suelos-Aplicaciones, Tesis de licenciatura en Ciencias Físicas, Facultad de Ciencias Exactas. UNCPBA, 101 pp., 1999.

Chaparro, M. A. E., C. S. Gogorza, Sinito, and J. M. Lirio, "Aumento Magnético" en Suelos Incendiados. Resumen expandido, Actas de Trabajos XX Reunión Científica de Geofísica and Geodesia, 166-170, 2000

Chaparro, M. A. E., C. S. Gogorza, A. Lavat, S. Pazos, and A. M. Sinito, Preliminary Results of Magnetic Characterisation of Different Soils in 
Tandil Region (Argentina) Affected by the Pollution of Metallurgical Factory, Eur. J. Environ. Eng. Geophys., 7, 35-58, 2002a.

Chaparro, M. A. E., J. C. Bidegain, A. M. Sinito, C. S. Gogorza, and S Jurado, Comparison of Magnetic Studies of Soils and Stream-Sediments from Buenos Aires Province (Argentina) Applied to Pollution Analysis. Extended abstract for the International Symposium on Fundamental Rock Magnetism and Environmental Applications. Erice, Italy, n. 26: 25-27, 2002b.

Chaparro, M. A. E., J. C. Bidegain, A. M. Sinito, C. S. Gogorza, and S. Jurado, Preliminary Results of Magnetic Measurements on StreamSediments from Buenos Aires province, Argentina, Stud. Geophys. Geod., 47(1), 121-145, 2003.

Chaparro, M. A. E., J. C. Bidegain, A. M. Sinito, C. S. Gogorza, and S. Jurado, Magnetic Studies Applied to Different Environments (Soils and Stream-Sediments) from a Relatively Polluted Area in Buenos Aires Province, Argentina, Environ. Geol., 45(5): 654-664, 2004a.

Chaparro, M. A. E., J. C. Bidegain, A. M. Sinito, S. Jurado, and C. S Gogorza, Relevant Magnetic Parameters and Heavy Metals from Relatively Polluted Stream-sediments-Spatial Distribution along a Crosscity Stream in Buenos Aires Province, Argentina, Stud. Geophys. Geod., 48(3), 615-636, 2004b

Chaparro, M. A. E. and A. M. Sinito, An Alternative Experimental Method to Discriminate Magnetic Phases Using IRM Acquisition Curves and Magnetic Demagnetisation by Alternating Field. Brazilian J. Geophys., 22(1): 17-32, 2004.

Chaparro, M. A. E., J. M. Lirio, H. Nunez, C. S. G. Gogorza, and A. M. Sinito, Preliminary Magnetic Studies of Lagoon and Stream Sediments from Chascomús Area (Argentina)—Magnetic Parameters as Pollution Indicators and Some Results of Using an Experimental Method to Separate Magnetic Phases, Environ. Geol., 49(1), 30-43, 2005.

Chaparro, M. A. E., Estudio de Parámetros Magnéticos de Distintos Ambientes Relativamente Contaminados en Argentina y Antártida, MONOGRAFIAS, Geofísica UNAM, Monografía No. 7, 107 pp., 2006.

Chirinos, L., N. L. Rose, R. Urrutia, P. Munoz, F. Torrejón, L. Torres, F. Cruces, A. Araneda, and C. Zaror, Environmental evidence of fossil fuel pollution in Laguna Chica de San Pedro lake sediments (Central Chile), Environ. Pollut., 141(2), 247-256, 2006.

Colombo, J. C., C. Bilos, and P. Landoni, Sources, distributions and variability of airborne particles and Hydrocarbons in La Plata city area, Argentina, Environ. Pollut., 104, 305-314, 1999.

Colombo, J. C., N. Cappelletti, A. Barreda, M. C. Migoya, and C. N. Skorupka, Vertical fluxes and accumulation of PCBs in coastal sediments of the Río de la Plata estuary, Argentina, Chemosphere, 61(9), 1345-1357, 2005.

Dangavs, N. V., A. M. Blasi, and D. M. Merlo, Geolimnología de laguna Chascomús, Provincia de Buenos Aires, Argentina, Revista Museo La Plata (NS), Geología, XI(112), 157-166, 1996.

Das, B. K., Environmental pollution impact on water and sediments of Kumaun lakes, Lesser Himalaya, India: a comparative study, Environ. Geol., 49(2), 230-239, 2005.

Desenfant, F., E. Petrovský, and P. Rochette, Magnetic signature of industrial pollution of stream sediments and correlation with heavy metals: case study from South France, Water, Air and Soil Pollut., 152(1), 297312, 2004.

Durza, O., Heavy contamination and magnetic susceptibility in soils around metallurgical plant, Phys. Chem. Earth (A), 24(6), 541-543, 1999.

Dunlop, D. J. and Ö. Özdemir, Rock magnetism. Fundamentals and frontiers, Cambridge University Press, Cambridge, 573 pp., 1997.

Environmental Protection Agency, EPA SW-846, Method 3050 Acid digestion of sediments, sludges and soils, Chapter 3: Metallic analysis, volume one, section A, part 1 of test methods for evaluating solid waste, Washington D.C., 1986.

Evans, M. E. and F. Heller, Environmental magnetism, Principles and applications of enviromagnetics, Academic Press. An imprint of Elsevier Science (USA). 299 pp., 2003.

Fakayode, S. O. and B. I. Olu-Owolabi, Heavy metal contamination of roadside topsoil in Osogbo, Nigeria: its relationship to traffic density and proximity to highways, Environ. Geol., 44, 150-157, 2003.

Fidalgo, F. and O. Martinez, Algunas caracterïsticas geomorfolögicas dentro del partido de La Plata, Provincia de Buenos Aires, Revista de la Asociaciön Geolögica Argentina, Buenos Aires, 38(2), 263-273, 1983.

Flanders, P. J., Collection, measurement, and analysis of airborne magnetic particulates from pollution in the environment, J. Appl. Phys., 75(10), 5931-5936, 1994.

Frink, C. R., A perspective on metals in soils, J. Soil Contamination, 5(4),
329-359, 1996.

Gautam, P., U. Blaha, and E. Appel, Integration of magnetic properties and heavy metal chemistry to quantify environmental pollution in urban soils, Kathmandu, Nepal, Himalayan J. Sci., 2(4), 140-141, 2004a.

Gautam, P., U. Blaha, E. Appel, and G. Neupane, Environmental magnetic approach towards the quantification of pollution in Kathmandu urban area, Nepal, Phys. Chem. Earth, 29(13-14), 973-984, 2004b.

Gautam, P., U. Blahab, and E. Appel, Magnetic susceptibility of dustloaded leaves as a proxy of traffic-related heavy metal pollution in Kathmandu city, Nepal, Atmospheric Environ., 39, 2201-2211, 2005.

Georgeaud, V. M., P. Rochette, J. P. Ambrosi, D. Vandamme, and D. Williamson, Relationship between heavy metals and magnetic properties in a large polluted catchment: the Etang de Berre (South of France), Phys Chem. Earth, 22(1-2), 211-214, 1997.

Gioia, S. M. C. L., M. M. Pimentel, M. Tessler, E. L. Dantas, J. E. G. Campos, E. M. Guimaraes, M. T. S. Maruokaa, and E. L. C. Nascimento, Sources of anthropogenic lead in sediments from an artificial lake in Brasília_central Brazil, Sci. Tot. Environ., 356(1-3), 125-142, 2006.

Goddu, S. R., E. Appel, D. Jordanova, and F. Wehland, Magnetic properties of road dust from Visakhapatnam (India) - Relationship to industrial pollution and road traffic, Phys. Chem. Earth., 29, 985-995, 2004.

Hanesch, M. and R. Scholger, Mapping of heavy metal loadings in soils by means of magnetic susceptibility measurements, Environ. Geol., 42, 857-870, 2002.

Heller, F., Z. Strzyszcz, and T. Magiera, Magnetic record of industrial pollution in soils of Upper Silesia, Poland, J. Geophys. Res., 103(B8), 17767-17774, 1998

Hoffmann, V., M. Knab, and E. Appel, Magnetic susceptibility mapping of roadside pollution, J. Geochem. Int., 66(1-2), 313-326, 1999

Hu, S., Y. Wang, E. Appel, Y. Zhu, V. Hoffmann, C. Shi, and Y. Yu, Magnetic responses to acidification in Lake Yangzonghai, SW China, Phys. Chem. Earth, 28, 711-717, 2003.

Hunt, A., J. Jones, and F. Oldfield, Magnetic measurements and heavy metals in atmospheric particulates of anthropogenic origin, Sci. Total Environ., 33, 129-139, 1984

Johnson, R. A. and D. W. Wichern, Applied Multivariate Statistical Analy sis, Third edition, Prentice-Hall, Inc, New Jersey (USA), 642 pp., 1992.

Jordanova, N. V., D. V. Jordanova, L. Veneva, K. Andorova, and E. Petrovský, Magnetic response of soils and vegetation to heavy metal pollution-A case of study, Environ. Sci. Tech., 37, 4417-4424, 2003a. Jordanova, D. V., L. Veneva, and V. Hoffmann, Magnetic susceptibility screening of anthropogenic impact on the Danube river sediments in Northwestern Bulgaria—preliminary results, Studia Geophys. Geod., 47, 403-418, 2003b

Jordanova, D. V., V. Hoffmann, and K. Thomas Fehr, Mineral magnetic characterization of anthropogenic magnetic phases in the Danube river sediments (Bulgarian part), Earth and Planet. Sci. Lett., 221, 71-89, 2004.

Jung, H-B., S-T. Yun, B. Mayer, S-O. Kim, S-S. Park, and P-K. Lee, Transport and sediment-water partitioning of trace metals in acid mine drainage: an example from the abandoned Kwangyang $\mathrm{Au}-\mathrm{Ag}$ mine area, South Korea, Environ. Geol., 48(4-5), 437-449, 2005.

Kapicka, A., E. Petrovský, S. Ustjak, and K. Machácková, Proxy mapping of fly-ash pollution of soils around a coal-burning power plant: a case study in Czech Republic, J. Geochem. Explor., 66, 291-297, 1999.

King, J., S. K. Banerjee, J. Marvin, and Özdemir, Ö., A comparison of different magnetic methods for determining the relative grain size of magnetite in natural materials: Some results from lake sediments, Earth Planet. Sci. Lett., 59, 404-419, 1982.

Knab, M., E. Appel, and V. Hoffmann, Separation of the anthropogenic portion of heavy metal contents along a highway by means of magnetic susceptibility and fuzzy c-means cluster analysis, Eur J. Environ. Eng. Geophys., 6, 125-140, 2001.

Knab, M., V. Hoffmann, E. Petrovsky, A. Kapicka, N. Jordanova, and E. Appel, Surveying the anthropogenic impact of the Moldau river sediments and nearby soils using magnetic susceptibility, Environ. Geol., 49, 527-535, 2006

Kukier, U., C. Fauziah Ishak, M. E. Summer, and W. P. Miller, Composition and element solubility of magnetic and non-magnetic fly ash fractions, Environ. Pollut., 123, 255-266, 2003.

Le Borgne, E., Susceptibilité magnétique anormale du sol superficiel, Ann Géophys., II, 399-419, 1955.

Lecoanet, H., F. Léveque, and J.-P. Ambrosi, Combination of magnetic parameters: an efficient way to discriminate soil-contamination sources (south France), Environ. Pollut., 122, 229-234, 2003. 
Phys. Earth Planet. Int., 42, 76-92, 1986

Maher, B. A., R. Thompson, and M. W. Hounslow, Introduction, in Quaternary Climate, Environments and Magnetism, edited by B. A. Maher and R. Thompson, pp. 1-48, Cambridge University Press, Cambridge, 1999.

Magiera, T. and Z. Strzyszcz, Ferrimagnetic minerals of anthropogenic origin in soils of some Polish national parks, Water, Air Soil Pollut., 124, 37-48, 1999.

Magiera, T., Z. Strzyszcz, A. Kapicka, E. Petrovsky, and MAGPROX TEAM, Discrimination of lithogenic and anthropogenic influences on topsoil magnetic susceptibility in Central Europe, Geoderma, 130, 299 311, 2006.

Manassero, M., C. Camillon, and A. Ronco, Sedimentologia and geoquimica de metales pesados de fondo de arroyos de la vertiente del Río de La Plata, Provincia de Buenos Aires, VII Reunión Argentina de Sedimentología-Actas, pp. 69-78, 1998

Mardia, K., Multivariate Analysis, Academic Press, Inc., New York (USA), 1980.

Matzka, J. and B. A. Maher, Magnetic biomonitoring of roadside tree leaves: identification of spatial and temporal variations in vehiclederived particulates, Atm. Environ., 33, 4565-4569, 1999.

Mazzeo, N. A., L. E. Venegas, and H. Choren, Analysis of NO, $\mathrm{NO}_{2}, \mathrm{O}_{3}$ and NOx concentrations measured at a green area of Buenos Aires City during wintertime, Atm. Environ., 39, 3055-3068, 2005.

Morris, W. A., J. K. Versteeg, C. H. Marvin, B. E. McCarry, and N. A. Rukavina, Preliminary comparisons between magnetic susceptibility and polycyclic aromatic hydrocarbons content in sediments from Hamilton Harbour, western Lake Ontario, Sci. Total Environ., 152, 153160,1994

Mullins, C. E. and M. S. Tite, Magnetic viscosity, quadrature susceptibility and frequency dependence of susceptibility in single-domain assemblages of magnetite and maghaemite, J. Geophys. Res., 78, 804-809, 1973.

Mullins, C. E., Magnetic susceptibility of the soil and its significance in Soil Science: a review, J. Soil Sci., 28, 223-246, 1977.

Park, S-S., S-O. Kim, S-T. Yun, G-T. Chae, S-Y. Yu, S. Kim, and Y. Kim, Effects of land use on the spatial distribution of trace metals and volatile organic compounds in urban groundwater, Seoul, Korea, Environ. Geol., 48(8), 1116-1131, 2005.

Petrovský, E., A. Kapicka, K. Zapletal, E. Sebestová, T. Spanilá, M. J. Dekkers, and P. Rochette, Correlation between magnetic properties and chemical composition of lake sediments from northern Bohemia, Preliminary study, Phys. Chem. Earth (A), 23(9-10), 1123-1126, 1998.

Petrovský E. and B. Elwood, Magnetic monitoring of air, land and water pollution, In Quaternary Climates, Environment and Magnetism, edited by B. A. Maher and R. Thompson, Cambridge University Press, pp. 279-322, 1999.

Petrovský, E., A. Kapicka, N. Jordanoa, M. Knob, and V. Hoffmann, Low field susceptibility: a proxy method of estimating increased pollution of different environmental systems, Environ. Geol., 39(3-4), 312-318, 2000.

Pozza, M. R., J. I. Boyce, and W. A. Morris, Lake-based magnetic mapping of contaminated sediment distribution, Hamilton Harbour, Ontario, Canada, J. Applied Geophys., 57, 23-41, 2004.

Quaranta, N., C. Grasselli, and J. Ferrante, Federal network of environmental monitoring in Argentina, in Air Pollution X., edited by C. A. Brebbia and J. F. Martin-Duque, pp. 361-369, ISBN 1-85312-916-X, 2002.

Ronco, A., C. Sobrero, G. Bulus Rosini, P. Alzuet, and B. Dutka, Screening for sediment toxicity in the Río Santiago Basin: a baseline study, Environ. Toxicology and Water Quality, 10, 35-39, 1995.

Ronco, A., C. Camilon, and M. Manassero, Geochemistry of heavy metals in bottom sediments from streams of the western coast of the Río de la Plata estuary, Argentina, Environ. Geochem. and Health, 23, 89-103, 2001.

Rosales Hoz, L., A. Carranza Edwards, S. Santiago Perez, and E. Morales
De La Garza, Spatial trends in the geochemical composition of sediments in the Panuco River discharge area, Gulf of Mexico, Environ. Geol., 48, 496-506, 2005.

SAGyP-INTA, Mapa de Suelos de la Provincia de Buenos Aires. Escala 1:500.000, Buenos Aires.—Proyecto PNUD ARG 85/019. 527 pp. 1989.

Schibler, L., T. Boyko, M. Ferdyn, B. Gajda, S. Höll, N. Jordanova, W. Rösler, and the Magprox team, Topsoil magnetic susceptibility mapping: data reproducibility and compatibility, measurement strategy, Stud. Geophys. Geod., 46, 43-57, 2002.

Scholger, R., Heavy metal pollution monitoring by magnetic susceptibility measurements applied to sediments of the river Mur (Styria, Austria), Eur. J. Environ. Eng. Geophys., 3, 25-37, 1998.

Spiteri, C., V. Kalinski, W. Rösler, V. Hoffmann, E. Appel, and MAGPROX team, Magnetic screening of a pollution hotspot in the Lausitz area, Eastern Germany: correlation analysis between magnetic proxies and heavy metal contamination in soils, Environ. Geol., 49, 1-9, 2005.

STATISTICA, STATISTICA for Windows (volumen III): Statistics 2nd edition, StatSoft(R), Tulsa (USA). 782 pp., 1995.

Strzyscz, Z., Magnetic susceptibility of soils in the areas influenced by industrial emission, in Soil Monitoring, pp. 255-269., Basel, Monte Verita, Birkhauser Veralg, 1993.

Strzyszcz, Z., T. Magiera, and F. Heller, The influence of industrial immisions on the magnetic susceptibility of soils in Upper Silesia, Stud. Geoph. Geod., 40, 276-286, 1996.

Szczucinski, W., P. Niedzielski, G. Rachlewicz, T. Sobczynski, A. Zioła A. Kowalski, S. Lorena, and J. Siepak, Contamination of tsunami sediments in a coastal zone inundated by the 26 December 2004 tsunami in Thailand, Environ. Geol., 49(2), 321-331, 2005.

Thompson, R., J. Bloemendal, J. Dearing, F. Oldfield, J. Rummery, J. Stober, and G. Turner, Environmental applications of magnetic measurements, Science, 207(4430), 481-486, 1980.

Thompson, R. and F. Oldfield, Environmental Magnetism, Allen \& Unwin (Publishers) Ltd. 225 pp., 1986.

Tite, M. and R. Linington, Effect of climate on the magnetic susceptibility of soils, Nature, 256, 565-566, 1975.

Vadiunina, A. F. and V. F. Babanin, Magnetic susceptibility of some soils in the U.S.S.R. Soviet, Soil Sci., 6, 106-110, 1972.

Vassilev, S. V., Phase mineralogy studies of solid waste products from coal burning at some Bulgarian thermoelectric power plants, Fuel, 71, 625633, 1992.

Versteeg, J. K., W. A. Morris, and N. A. Rukavina, The utility of magnetic properties as a proxy for mapping contamination in Hamilton Harbour, J. Great Lakes Res., 21, 71-83, 1995.

Wang, X-S. and Y. Qin, Correlation between magnetic susceptibility and heavy metals in urban topsoil: a case study from the city of Xuzhou, China, Environ. Geol., 49(1), 10-18, 2005.

Wang, X-S. and Y. Qin, Magnetic properties of urban topsoils and correlation with heavy metals: a case study from the city of Xuzhou, China, Environ. Geol., 49, 897-904, 2006a.

Wang, X-S. and Y. Qin, Spatial distribution of metals in urban topsoils of Xuzhou (China): controlling factors and environmental implications, Environ. Geol., 49, 905-914, 2006b.

Yuce, G., A. Pinarbasi, S. Ozcelik, and D. Ugurluoglu, Soil and water pollution derived from anthropogenic activities in the Porsuk River Basin, Turkey, Environ. Geol., 49, 359-375, 2006.

Zhang, W. and L. Yu, Relationships between magnetic properties and heavy metals in inter-tidal sediments of the Yangtze Estuary, China, Extended abstract for the International Symposium on Fundamental Rock Magnetism and Environmental Applications, Erice, Italy, 195197, 2002.

M. A. E. Chaparro (e-mail: chapator@exa.unicen.edu.ar), C. S. G Gogorza, M. A. E. Chaparro, M. A. Irurzun, A. M. Sinito 